\title{
PROSPECÇÃO TECNOLÓGICA PARA A COMUNICAÇÃ̃ IMEDIATA ENTRE SURDOS E OUVINTES
}

\author{
TECHNOLOGY PROSPECTION FOR IMMEDIATE COMMUNICATION \\ BETWEEN THE DEAF AND THE HEARING
}

\author{
Joelson Conceição da Silva* \\ Henrique Rego da Hora** \\ Rogério Atem de Carvalho ${ }^{* * *}$
}

\section{Resumo}

O objetivo deste trabalho é apresentar os resultados de uma pesquisa sobre os depósitos de patentes de dispositivos que permitem a comunicação instantânea entre surdos e ouvintes e de produção acadêmica sobre esse tema. Para isso foram utilizadas as bases de depósito de patentes do INPI e o sistema Questel Orbit ${ }^{\circledR}$. A mesma estratégia de pesquisa foi aplicada ao Scopus na busca de trabalhos e artigos publicados sobre tais tecnologias. Os depósitos de patentes de invenções foram encontrados a partir das palavras-chave: "comunicação imediata" e "surdos" no Questel Orbit ${ }^{\circledR}$, a maioria depositada por empresas de comunicação ou Institutos de Tecnologia. Nos Estados Unidos da América do Norte e na China muito vem sendo produzido sobre o tema, diferente do que ocorre no Brasil. A falta de investimento em $P \& D$ e em estudos de melhoria no que já existe, tem favorecido a dependência do Brasil em tecnologia estrangeira nessa área.

Palavras-chave: Surdez. Patentes. Comunicação.

\section{Introdução}

No ano de 2017 o tema da redação do Exame Nacional do Ensino Médio (Enem) foi: "Desafios para a formação educacional de surdos no Brasil". A surpresa em relação ao tema fez surgir questionamentos em diversos setores da sociedade, ultrapassando a temática proposta na redação do ENEM e tocando em um ponto crucial para a integração

\footnotetext{
${ }^{*}$ Mestrando em Propriedade Intelectual e Transferência de Tecnologia para a Inovação. Professor da Rede oficial de ensino do Estado do Rio de Janeiro - SEEDUC-RJ. E-mail: joelsonconceicao@uol.com.br

** Doutor em Engenharia de Produção. Professor Adjunto do IFF - Instituto Federal Fluminense. E-mail: dahora@gmail.com

*** Doutor em Engenharia de Produção. Professor Titular do IFF - Instituto Federal Fluminense. E-mail: ratembr@gmail.com
} 
dos surdos à sociedade: a comunicação entre pessoas surdas e ouvintes em uma sociedade formada majoritariamente por pessoas ouvintes. Segundo o censo do Instituto Brasileiro de Geografia e Estatística (IBGE, 2012), há cerca de 10 milhões de surdos no Brasil, entre os que nasceram surdos e aqueles que perderam a audição ao longo do tempo. Esse número tende a aumentar, de acordo com dados da Organização Mundial da Saúde (2014), 10\% da população mundial apresenta alguma perda auditiva, sendo significativa a quantidade de pessoas cuja perda a audição se relaciona a uma exposição excessiva a ruídos.

As dificuldades enfrentadas pelo surdo em seus ambientes de estudo, trabalho ou lazer, começam pela ausência da linguagem oral e pelo desconhecimento, por boa parte da população ouvinte, da Língua Brasileira de Sinais (Libras), a língua materna dos surdos, utilizada no Brasil. Isso resulta em uma inevitável dificuldade de comunicação entre ouvintes e surdos. Segundo Smole e Diniz (2002):

É por intermédio da comunicação que informaçães e conceitos são
repassados entre as pessoas, sendo a comunicação oral o recurso mais
acessível, ágil e direto, que permite a convivência coletiva mediante o
exercício da escuta entre os que se relacionam. Admite-se a
comunicação como um processo ocorrente em duas vias, sendo
necessário um entendimento daquilo que foi dito por ambos os
participantes da informação, ou seja, não há comunicação quando o
receptor não compreende o que lhe foi revelado.

Em uma sociedade tão plural e tecnológica como a atual, há pesquisas e estudos de dispositivos que permitem a pessoas portadoras de deficiência sua integração à sociedade. Entretanto "o mesmo não acontece no caso específico da comunicação entre surdos e ouvintes quando um deles ou ambos não domina a língua de sinais" (CASTRO; COBBE; GOEDERT, 2015).

O objetivo deste artigo é apresentar os resultados de uma prospecção sobre as tecnologias e invenções que permitam a comunicação entre ouvintes e surdos, de forma imediata, mesmo sem que um deles não domine a língua de sinais. Procurou-se consultar as bases de registros de patentes para melhor conhecer o que se tem pesquisado e escrito, no mundo, sobre o assunto, para então mapear onde e quando houve depósito de patentes de dispositivos tecnológicos que visem esse objetivo de comunicação imediata. 


\section{Revisão da literatura}

Entre as muitas variáveis que se deve levar em conta quando se trata do tema “surdez”, segundo Bevilacqua e Moret (2005), a mais conhecida é a concepção médica da surdez, diagnosticada por médicos e fonoaudiólogos, e que irá descrever uma visão não só funcional como também orgânica da perda auditiva (NERI, 2003).

Muitas são as dificuldades enfrentadas pelo surdo, a começar pela ausência da linguagem oral que, de acordo com Diniz e Smole (2002), originou "uma terminologia preconceituosa que circula muito frequentemente na sociedade: surdo-mudo". As dificuldades de comunicação entre surdos e ouvintes nos diversos ambientes da sociedade impedem que os surdos exerçam, plenamente, a sua cidadania, ou ainda que possa ter "perspectivas de uma vida digna e [...] inclusão social” (SILVA; KAUCHAKJE; GESUELI, 2003a).

Diversos são os dispositivos tecnológicos, portáteis ou não, que vem sendo criados ao longo dos anos e aperfeiçoados para que possam ajudar, de alguma forma, as pessoas surdas. O que se percebe, porém, é que os pesquisadores que desenvolvem projetos no campo da acessibilidade, parecem se concentrar nos problemas de pessoas paraplégicas, ou ainda, de outras deficiências físicas, dando menos atenção a projetos relacionados à surdez, que permitam aos surdos, segundo De Jesus et al (2016, p. 2), “a comunicação instantânea entre todos". Sobre o tema, o mesmo autor observa que os aplicativos existentes para a tradução entre a língua portuguesa e a língua de sinais, Libras,

[...] necessitam de acesso à internet (que na situação do Brasil tem o grande problema da quantidade de dados móveis) não contando que a comunicação não é estabelecida, pois com esses apps os surdos conseguem entender o que os falantes querem transmitir, entretanto, o contrário não é estabelecido (DE JESUS et al., 2016).

Já há na internet ambientes virtuais para o ensino da Língua Brasileira de Sinais para surdos e para os não surdos que desejam aprender ou aperfeiçoar-se em LIBRAS que utiliza configuração de mãos e movimento - o que demanda tempo e dedicação do aluno - cujo número ainda pequeno de pessoas possui o domínio da técnica (MARCATO; MARCONI; LIMA, [s.d.]). Ainda no contexto da surdez, dispositivos luminosos como campainhas, relógios vibratórios que servem como despertadores e aparelhos de telefone desenvolvidos especialmente para surdos já estão disponíveis no mercado. Da mesma forma salas de bate papo, catálogos de busca, sistemas de closed caption sejam eles online 
ou offline e outras ferramentas virtuais já se ocuparam de evitar a exclusão dos surdos da era digital (SILVA; KAUCHAKJE; GESUELI, 2003b).

Entretanto prospectando tecnologias para surdos, nota-se uma ausência de idéias de dispositivos capazes de realizar a comunicação entre os que falam e aqueles que não conseguem ouvir em ambientes não virtuais. A prospecção tecnológica pode ser definida como um meio sistemático de mapear desenvolvimentos científicos e tecnológicos futuros capazes de influenciar de forma significativa uma indústria, a economia ou a sociedade como um todo (QUINTELLA et al., 2011)

\section{Metodologia}

Para realizar esta pesquisa foram consultados diversos trabalhos sobre o tema na base de conhecimento Scopus ${ }^{\circledR}$, onde as palavras chave deaf, device, communication e immediate foram utilizadas assim como os tesauros deafened, earless, prompt, contact $\mathrm{e}$ instantaneus. Os documentos encontrados foram filtrados de acordo com a pertinência ao tema e em seguida organizados cronologicamente para que se pudesse ter uma visão do avanço em trabalhos publicados sobre o assunto.

Para a busca de registros de patentes desses dispositivos - portáteis ou não utilizou-se neste trabalho o sistema Orbit $^{\circledR}$ que é uma poderosa ferramenta de busca e análise de patentes. "É um produto desenvolvido pela empresa francesa Questel para busca e análise de informações contidas em patentes que provê acesso a informações de publicações de patentes de mais de 150 países" (STOCK; STOCK, 2005).

O Orbit foi escolhido por possibilitar fazer análises estatísticas e a geração de gráficos, mapas e diagramas sobre grandes conjuntos de patentes, empresas depositantes e inventores. A pesquisa foi realizada usando palavras-chave em inglês e seus tesauros. Após as buscas houve ainda uma classificação de patentes, status legal, depositantes e inventores por países. Já para a pesquisa na base do INPI - Instituto Nacional da Propriedade Industrial, que é a autarquia responsável pelo depósito de patentes de invenções que venham a ser protegidas no Brasil - foram utilizadas as palavras-chave em português: sistema, dispositivo, comunicação e surdos. Os procedimentos utilizados foram os seguintes: definição da amostra; definição das palavras-chave; pesquisa nas bases de dados citadas; coleta de dados; organização; análise e apresentação dos resultados. O filtro utilizado foram as palavras-chave no título ou no resumo do pedido de depósito. 


\section{Resultados}

Inicialmente foi feita uma busca de trabalhos e artigos publicados contendo as palavras-chave ou seus tesauros como mostra a tabela abaixo:

Tabela 1: termos utilizados para a pesquisa, 2018.

\begin{tabular}{|c|c|c|}
\hline $\begin{array}{c}\text { TITLE-ABS-KEY } \\
\text { (communication OR rapport) }\end{array}$ & Tesauros de B \\
\hline $\begin{array}{c}\text { TITLE-ABS-KEY } \\
\text { (immediate OR instantaneous) }\end{array}$ & & Tesauros de C \\
\hline $\begin{array}{c}\text { TITLE-ABS-KEY } \\
\text { (deaf OR deafened OR deafness) }\end{array}$ & & Tesauros de D \\
\hline
\end{tabular}

Fonte: elaborado pelos autores

Na figura 1 são apresentadas todas as intersecções possíveis entre os termos encontrados na base de conhecimento Scopus entre artigos, capítulos de livros e outras publicações no período de 1913 até 2018.

Figura 1: Diagrama de Venn com a quantidade de trabalhos encontrados na base Scopus, 2018.

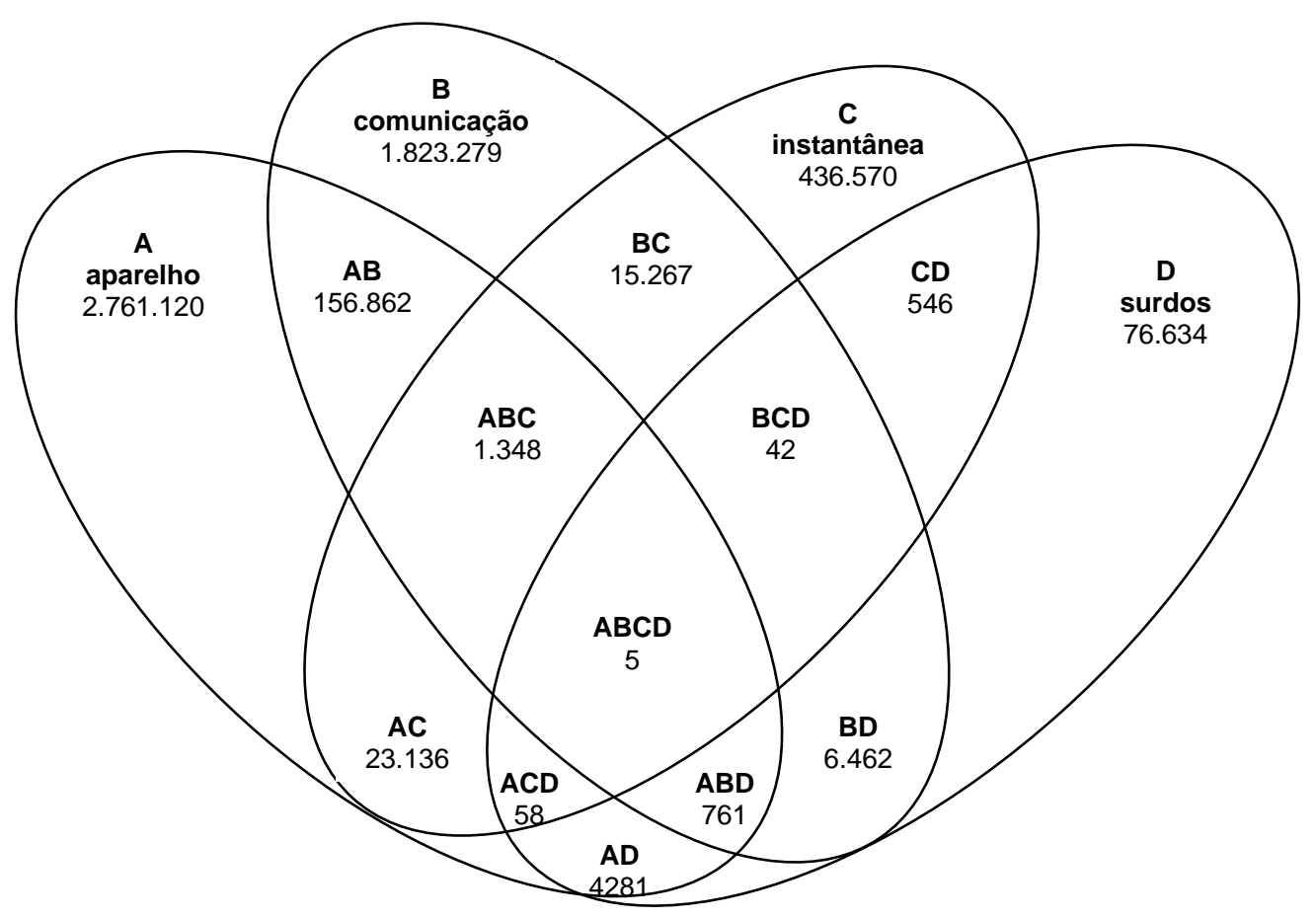

Fonte: Elaboração própria. 
Na figura 1 foi possível perceber que foram encontrados apenas cinco trabalhos na intersecção dos quatro termos o que confirma um grande déficit de trabalhos publicados nessa área. Um número maior de artigos aparece na intersecção BCD (comunicação, instantânea e surdos) e 4.281 artigos se ocupam de aparelhos para surdos (AD), porém nesse caso estão todos os trabalhos contendo qualquer tipo de dispositivo para surdos e não apenas aqueles destinados à comunicação imediata.

O gráfico 1 apresenta uma evolução cronológica dos trabalhos publicados sobre o assunto, seguido do gráfico 2 que apresenta os trabalhos publicados distribuídos por países.

Gráfico 1: Documentos por ano de publicação.

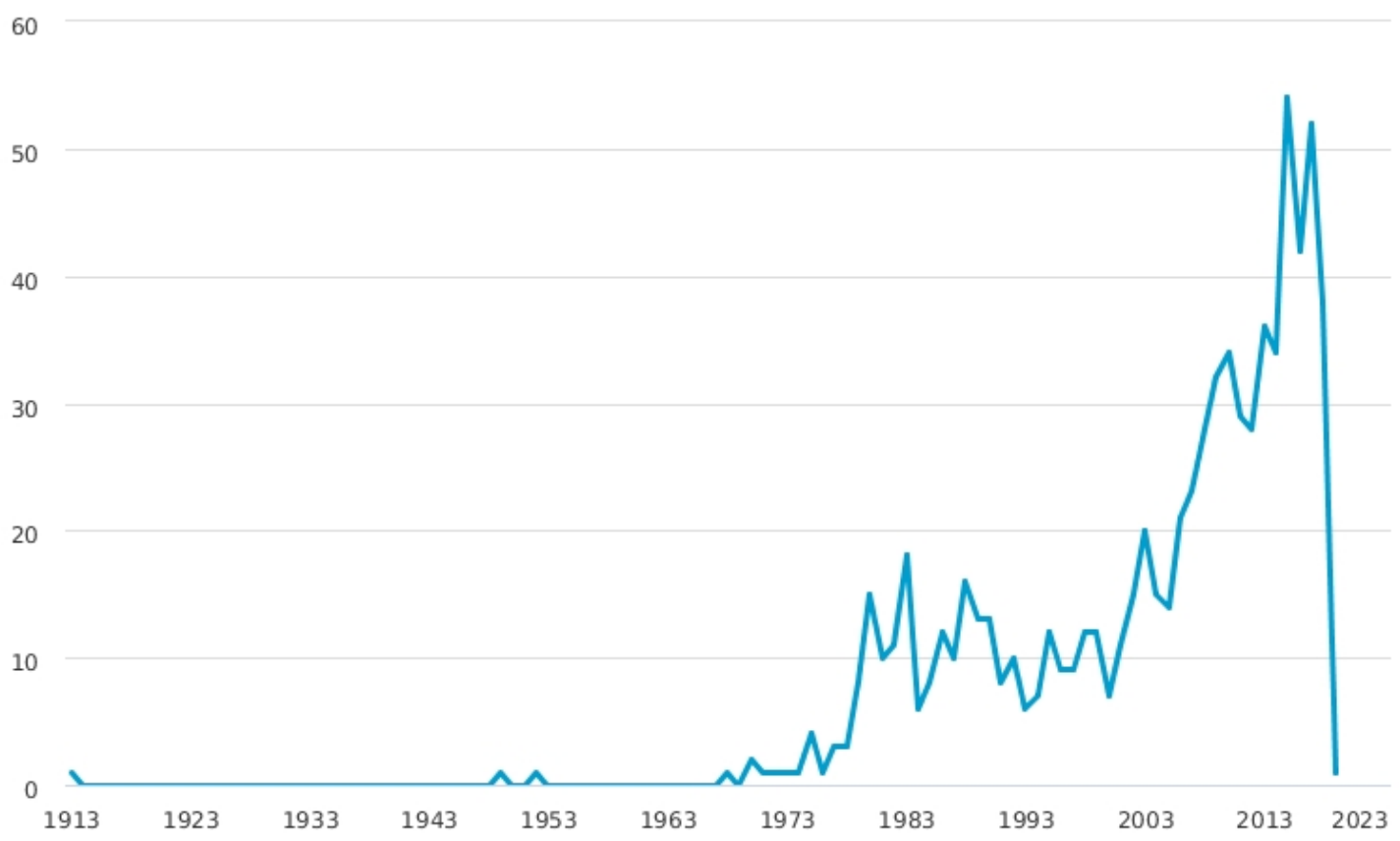

Fonte: Elaboração própria. 


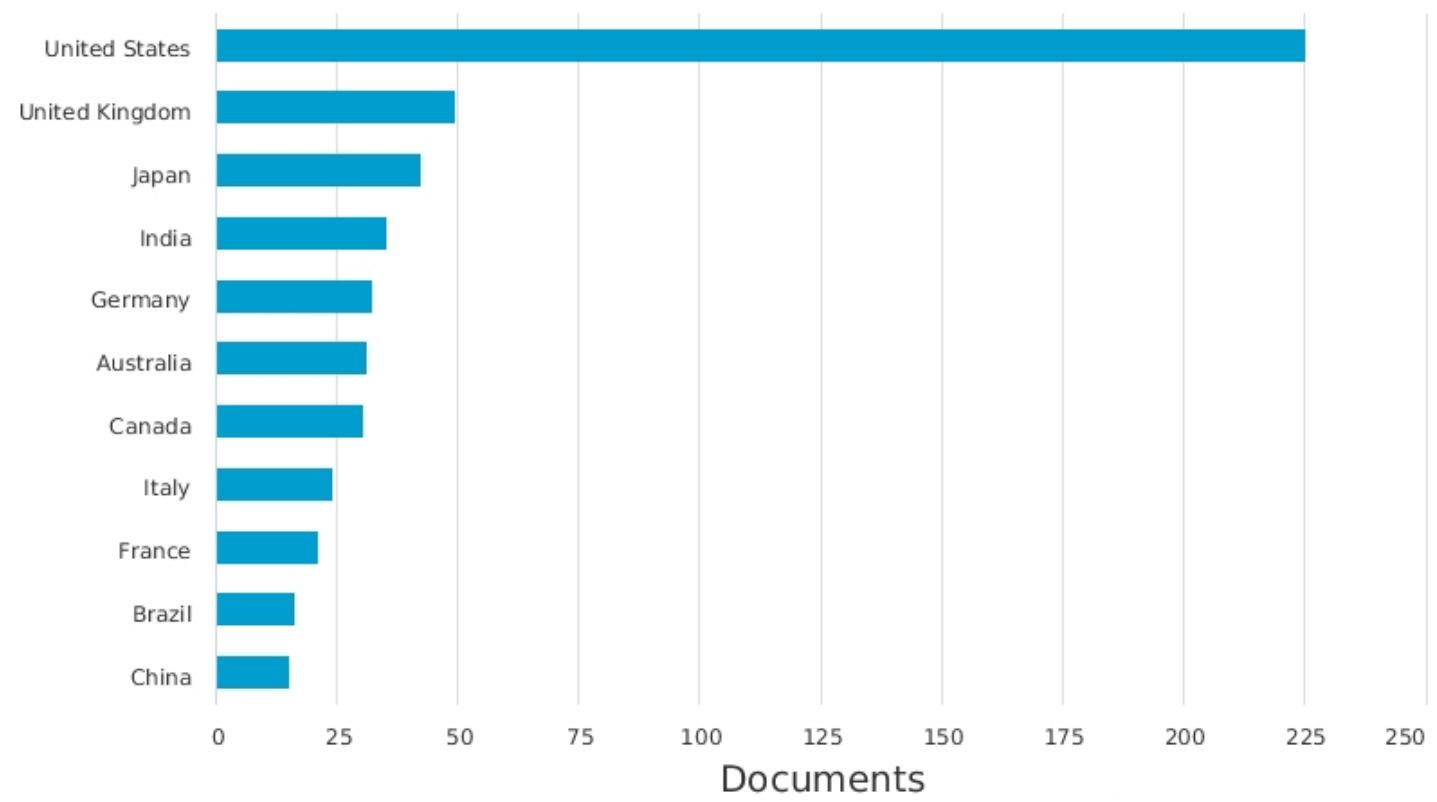

Gráfico 2: Documentos por país.

Fonte: Elaboração própria.

No gráfico 1 nota-se um aumento na publicação de trabalhos sobre o assunto a partir da década de 1960 e que houve um salto significativo a partir do ano 2000 onde o interesse pelo assunto cresceu ainda mais. Na sequência o gráfico 2 indica uma liderança dos Estados Unidos da América e do Reino Unido em documentos encontrados relacionados à temática desta pesquisa. Observamos que o Brasil também figura a lista como o $10^{\circ}$ país com maior número de documentos prospectados, seguido da China.

Já na busca de patentes dessas invenções, fizemos associações das mesmas palavras-chave no $\mathrm{Orbit}^{\circledR}{ }^{\circledR}$ com o objetivo de eliminar os resultados que não correspondem ao objeto desta prospecção e a associação device, communication, immediate e deaf apresentou o melhor resultado: 83 patentes encontradas.

O Gráfico 3 mostra que desses 83 resultados: 35 registros possuem o status alive - que indicam patentes ativas concedidas - somando-se a estas 8 pedidos de registro 
pendentes. As demais 40 patentes encontradas já apresentam status dead, indicando pedidos de depósitos negados, patentes expiradas ou caducadas.

Gráfico 3: Status legal da patente.

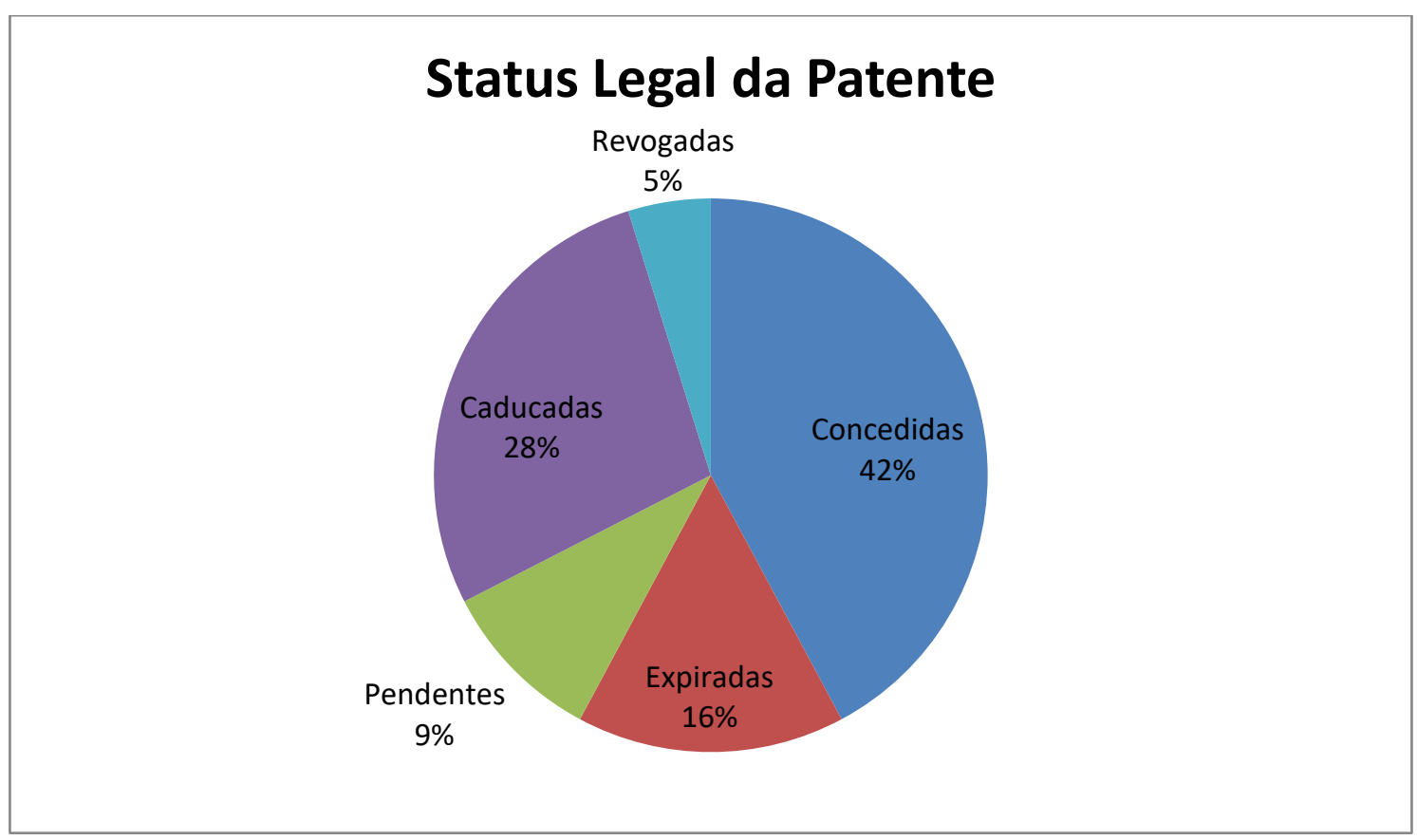

Fonte: Elaboração própria.

Ainda por meio do gráfico 3, nota-se que $42 \%$ das patentes encontradas foram concedidas e estão ativas em seus países de depósito, contra $28 \%$ de patentes caducadas, que significa "que a invenção patenteada passou para domínio público desde o momento no qual se produziram os fatos ou omissões que deram lugar à referida caducidade" (GAMA CERQUEIRA; RIO VERDE; NETO, 1982). Diversos são os motivos de caducidade da patente: "por expirar o prazo para o qual foram concedidas; por falta de pagamento de uma anuidade ou da taxa correspondente; se a invenção não é usada ou por renúncia do titular” (RODRIGUES, 1998).

Em seguida, a figura 2 apresenta uma nuvem de palavras indicando o volume de patentes associadas às diversas áreas do conhecimento. 
Figura 2: Nuvem de palavras

Patent families by Technology domain

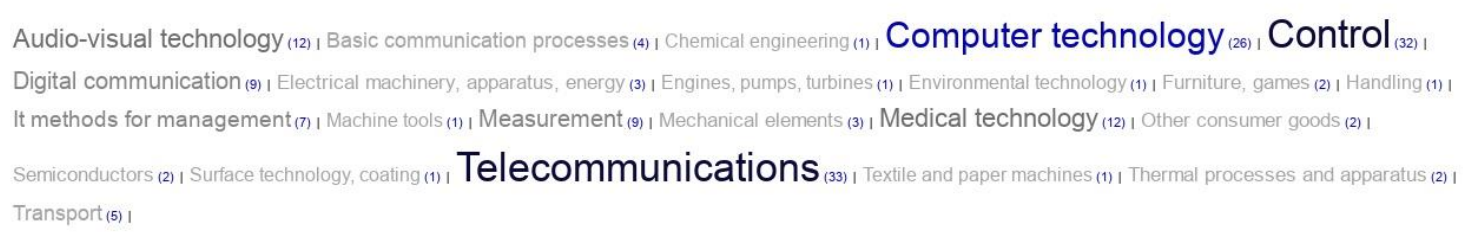

Fonte: Elaboração própria.

Percebe-se através da figura 2 uma convergência da maioria das patentes encontradas para a área de telecomunicações, seguida de tecnologia computacional, controle, tecnologia áudio visual e tecnologia médica. Na sequência o gráfico 4 apresenta contagem do número de patentes de invenções depositadas ao redor do mundo nos últimos 20 anos.

Gráfico 4: Número de patentes depositadas por ano.

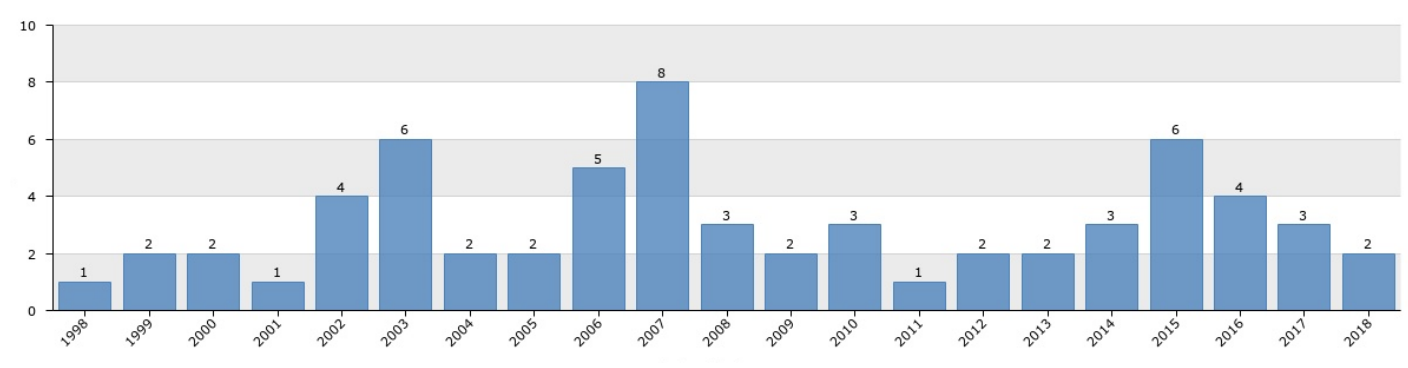

Fonte: Elaboração própria.

Através do gráfico 4 observa-se aumentos quase cíclicos do número de patentes ao longo desse período e que há um interesse contínuo nesse tipo de tecnologia, pois desde 1998 não houve um único ano em que não tenha sido apresentada pelo menos uma patente para depósito.

De posse do panorama da evolução de depósitos dessas invenções foi feito um levantamento, representado no gráfico 5, sobre quem são os depositantes ao redor do mundo nessa área. 
Gráfico 5: Depositantes das patentes.

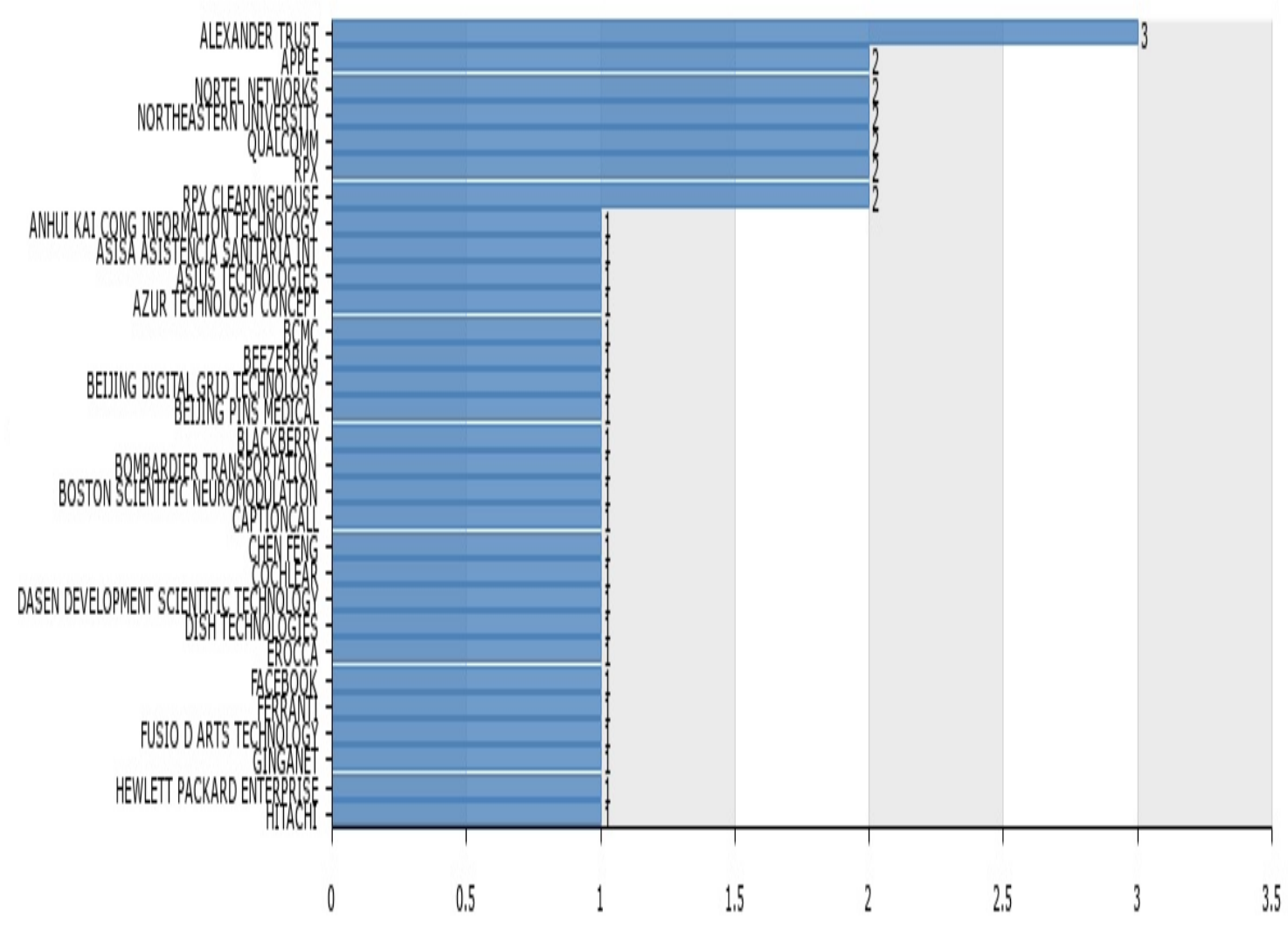

Fonte: Elabora ção própria.

Entre os depositantes estão universidades, centros de pesquisa tecnológica, empresas de telecomunicação e inventores sensíveis ao problema de comunicação com pessoas surdas. A lista é liderada pela Fundação Alexander Trust, fundada por Frederick Mathias Alexander que foi um ator e recitador nascido na Tasmânia em 1869 e que teve sua carreira interrompida pela perda de voz. "Sem ajuda vinda de médicos Alexander realizou um exame intensivo de si mesmo e após um longo período de pesquisa ele curou a si mesmo e decidiu ajudar aos outros"(ALEXANDER, 1990).

Sobre os países onde essas patentes foram inicialmente depositadas, o gráfico 6 mostra um interesse maior em proteger as invenções nos Estados Unidos da América e na China. 
Gráfico 6: Depósitos de Patentes

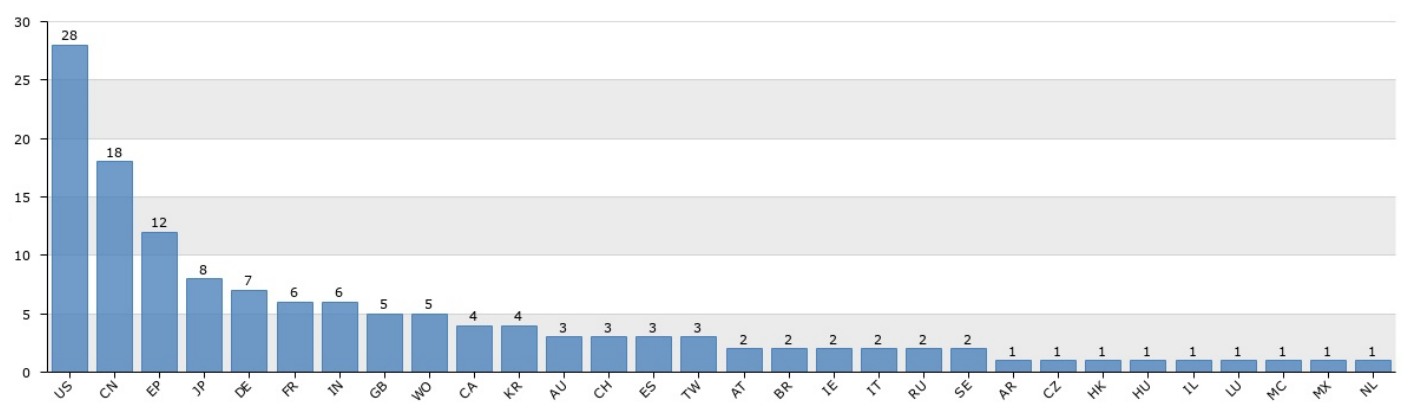

Fonte: Elaboração própria.

O gráfico 6 ainda revela muitos outros países com invenção protegida, como o Brasil.

A pesquisa na base do INPI resultou em apenas cinco pedidos de patentes, sendo o mais antigo depositado em 1991 e o mais recente em 2010 e nenhum destes foi concedido até outubro de 2018, quando foi feita a consulta. Na tabela o status dos depósitos dessas patentes pode ser visualizado.

Tabela 2: Status dos depósitos das patentes.

\begin{tabular}{|l|l|l|}
\hline \multicolumn{1}{|c|}{ NÚMERO DO PEDIDO } & \multicolumn{1}{|c|}{ DATA DO DEPÓSITO } & \multicolumn{1}{c|}{ STATUS } \\
\hline$\underline{\text { PI 9904219-3 }}$ & $22 / 09 / 1999$ & Pedido arquivado \\
\hline$\underline{\text { PI 0201374-6 }}$ & $25 / 02 / 2002$ & Pedido arquivado \\
\hline$\underline{\text { PI 0502931-7 }}$ & $24 / 06 / 2005$ & Pendente \\
\hline$\underline{\text { PI 0601633-2 }}$ & $24 / 03 / 2006$ & Pedido arquivado \\
\hline$\underline{\text { PI 1000633-8 }}$ & $17 / 02 / 2010$ & Pendente \\
\hline
\end{tabular}

Fonte: Elaboração própria.

Dos depósitos de patente encontrados na base do INPI, quatro foram depositados por inventores e apenas um por empresa. O contrário não acontece no panorama mundial, pois de acordo com a pesquisa no Questel Orbit são as empresas de telecomunicação e Institutos de tecnologia os que lideram pedidos de patentes deste tipo de dispositivo ao redor do mundo. Essa falta de investimento das empresas no Brasil em pesquisa e inovação nessa área indica uma possível dependência futura de tecnologia estrangeira na 
comunicação imediata entre surdos e ouvintes, já que grandes empresas norte americanas e chinesas estão investindo nessa temática, seguidas de outras ao redor do mundo.

Seguindo a lógica das patentes, os artigos pesquisados sobre o assunto também apontam países como os Estados Unidos da América, a China, o Japão e países da União Europeia liderando o número de trabalhos publicados sobre a comunicação entre pessoas surdas e ouvintes. Além do muito que se tem avançado em língua de sinais, é lugar comum afirmar que uma parcela significativa da população mundial não domina plenamente a comunicação gestual. E dessa forma, o aperfeiçoamento de dispositivos práticos de comunicação torna-se imprescindível.

\section{Considerações Finais}

Este trabalho possibilitou concluir que existem estudos publicados ao redor do mundo sobre dispositivos de comunicação instantânea entre pessoas surdas e ouvintes, porém poucos depósitos de patentes de tais dispositivos foram encontrados. Com a busca por patentes observamos que no Brasil, ao contrário de muitos outros países, as empresas - em especial as empresas de telecomunicação - não têm dado a devida importância em desenvolver este tipo de tecnologia, pois dos cinco pedidos de patentes encontrados na base do INPI apenas um deles foi depositado por um Instituto de tecnologia. Trata-se do Instituto Centro de Pesquisa e Desenvolvimento em Tecnologia de Software, situado no Distrito Federal, que realizou o depósito de uma patente de um dispositivo de comunicação que se utiliza texto e voz para a comunicação entre surdos e ouvintes. O pedido encontra-se arquivado no INPI.

A prospecção em patentes permitiu identificar que os demais depósitos de patentes no Brasil foram feitos pelos próprios inventores e nenhum deles foi concedido até Outubro de 2018, o que indica uma tendência em importar esse tipo de tecnologia para suprir a demanda no país. Ao contrário do Brasil, observa-se que países como os Estados Unidos da América, a China, e países da União Europeia já depositaram patentes dessas tecnologias de comunicação e algumas delas encontram-se com status ativo, o que significa que diversas empresas podem fabricar esses dispositivos e comercializá-los ao redor do mundo.

Para trabalhos futuros sugere-se a ampliação desse estudo utilizando outras bases de dados de produção científica assim como outras bases de patentes para refinar ainda 
mais a busca por novas tecnologias de comunicação, inclusive apontando o grau de maturidade de projetos de implantação de tecnologia em redes de comunicação entre pessoas surdas ou cegas e pessoas ouvintes e videntes.

\begin{abstract}
The aim of this paper is to present the results of a research on patenting devices that allow instant communication between deaf and hearing people and academic production on this subject. In order to do so, the INPI patent filing database and the Questel Orbit ${ }^{\circledR}$ system were used. The same research strategy was applied to Scopus in the search for works and published papers on such technologies. Patent filings for inventions were found through the keywords: "immediate communication" and "deaf" in Questel Orbit ${ }^{\circ}$, most of them filed by media companies or institutes of technology. In the United States of America and China, much has been produced on the subject, unlike in Brazil. The lack of investment in $\mathrm{R} \& \mathrm{D}$ and improvement studies in what already exists has favored Brazil's dependence on foreign technology in this area.
\end{abstract}

Keywords: Deafness. Patents. Communication.

\title{
Referências
}

ALEXANDER, F. M. The Alexander technique: the essential writings of $\mathbf{F}$. Matthias Alexander. [s.1.] Lyle Stuart, 1990.

BEVILACQUA, M. C.; MORET, A. L. M. Deficiência auditiva: conversando com familiares e profissionais da saúde. [s.l.] Pulso Editorial, 2005.

CASTRO, A. DE; COBBE, R. V.; GOEDERT, W. J. Prospecção de demandas tecnológicas. Manual Metodológico para o SNPA. Brasilia: Embrapa, 2015.

GAMA CERQUEIRA, J.; RIO VERDE, L. G.; NETO, J. C. C. Tratado da propriedade industrial. [s.1.] Editora Revista dos Tribunais, 1982. v. 2

DE JESUS, V. S. et al. LuBraS Dispositivo Eletrônico para Comunicação LIBRASLíngua Portuguesa. Mostra Nacional de Robótica (MNR), 2016.

RODRIGUES, A. A nova lei de patentes, a indústria química e a universidade. Química Nova, v. 21, n. 2, p. 229, 1998.

DINIZ, M. DE S.; SMOLE, K. S. Um professor competente para o ensino médio proposto pelos PCNEM. Educação Matemática em Revista: Edição especial: Formação de Professores, p. 39-43, 2002. 
IBGE, C. D. Características gerais da população, religião e pessoas com deficiência. Rio de Janeiro: IBGE, 2012.

MARCATO, S. A.; MARCONI, M. C.; LIMA, P. Um ambiente para a aprendizagem da lingua de sinais. p. 8, [s.d.].

NERI, M. C. Diversidade: retratos da deficiência no Brasil. São Paulo. FGV. 2003.

QUINTELLA, C. M. et al. Prospecção tecnológica como uma ferramenta aplicada em ciência e tecnologia para se chegar à inovação. Revista Virtual de Química, v. 3, n. 5, p. 406-415, 2011.

SAÚDE, O. M. DA. CID-10: Classificação Estatística Internacional de Doenças com disquete Vol. 1. [s.1.] Edusp, 2014.

SILVA, I. R.; KAUCHAKJE, S.; GESUELI, Z. M. Cidadania, surdez e linguagem: desafios e realidades. [s.1.] Plexus Editora, 2003a.

SILVA, I. R.; KAUCHAKJE, S.; GESUELI, Z. M. Cidadania, surdez e linguagem: desafios e realidades. [s.1.] Plexus Editora, $2003 \mathrm{~b}$.

STOCK, M.; STOCK, W. G. Intellectual property information. A case study of QuestelOrbit. Information Services \& Use, v. 25, n. 3-4, p. 163-180, 2005. 